\title{
Prevalência da realização do exame citopatológico do colo uterino, no Brasil, nos anos de 2007 e 2013
}

\author{
Prevalence of screening for cervical cancer in Brazil, in 2007 and 2013
}

\author{
Thais Vicentine Xavier ${ }^{1}$, William Bigliardi Zibetti ${ }^{1}$, Marcelo Fernandes Capilheira ${ }^{2}$
}

Xavier TV, Zibetti WB, Capilheira. Prevalência da realização do exame citopatológico do colo uterino, no Brasil, nos anos de 2007 e 2013 / Prevalence of screening for cervical cancer in Brazil, in 2007 and 2013. Rev Med (São Paulo). 2016 abr.-jun.;95(2):66-70.

RESUMO: Introdução: O câncer de colo uterino é causado pela infecção persistente por algumas cepas oncogênicas do Papiloma Vírus Humano. Ele acontece devido ao crescimento anormal de células que possuem a capacidade de invadir localmente e metastatizar à distância. $\mathrm{O}$ câncer cervical é o terceiro tumor mais frequente entre as mulheres e a quarta maior causa de morte por câncer nesta população. Por isso, o exame citopatológico de colo de útero mostra-se fundamental no rastreamento e diagnóstico precoce desta patologia, evitando, assim, que essa assuma um papel metastático. Objetivo: Determinar as prevalências da realização do exame citopatológico do colo uterino nos anos de 2007 e 2013, em todas regiões do Brasil, e compará-las. Métodos: O delineamento do estudo é do tipo transversal descritivo, com base em dados secundários da Vigilância de fatores de risco e proteção para doenças crônicas por Inquérito Telefônico(VIGITEL) dos anos de 2007 e 2013. O objetivo do VIGITEL é monitorar a frequência e distribuição dos principais determinantes das doenças crônicas nãotransmissíveis por inquérito telefônico. Esse questionário é realizado anualmente desde o ano de 2006 e, a partir de 2007, foram incluídas perguntas sobre prevenção de câncer, sendo os dados 2013 os últimos disponíveis até o momento. Essa pesquisa é realizada com maiores de 18 anos residentes das 26 capitais brasileiras e no Distrito Federal. O desfecho do presente estudo compreendeu a realização ou não do exame preventivo do câncer de colo uterino em algum momento da vida e nos últimos 3 anos, sendo incluídas as mulheres entre 25 e 64 anos. No ano de 2007 foram entrevistas 32704 mulheres e em 2013, 32653. Esses dados foram agrupados segundo ano e região para posterior análise. Resultados: Em 2007, do total de brasileiras entrevistadas, $84,67 \%$ responderam já ter realizado o exame de rastreio para câncer de colo uterino, enquanto $79,81 \%$ afirmaram tê-lo realizado nos últimos três anos. Por regiões, a Região Sul se destacou com percentuais de $92,85 \%$ e $88,21 \%$, para as mesmas variáveis. A Região Nordeste teve as piores taxas do país, com $80,12 \%$ e $75 \%$, respectivamente. A Região Sudeste apresentou altos índices, próximos ao Sul. O Centro-Oeste ficou em terceiro, superando Região Norte. Em 2013, 85,61\% das mulheres afirmaram já ter realizado o exame de rastreamento em algum momento da vida, e $80,68 \%$ responderam estar em dia com o exame. Por regiões, a Região Sul foi quem se destacou, com $92,75 \%$ das mulheres já tendo realizado o exame em algum momento e $87,81 \%$ estando em dia com o Papanicolau. A Região Nordeste teve o pior desempenho, com $80,8 \%$ e $75,59 \%$, respectivamente. Ainda, o Centro-Oeste foi suplantado pelo Norte, após melhora discreta deste último em relação à 2007. Discussão/Conclusão: As regiões Sul, Sudeste e CentroOeste mantiveram-se com altas taxas de realização do exame, semelhante a de países desenvolvidos. Em 2007, a região Norte que estava abaixo da cobertura de $80 \%$ estipulada pela OMS conseguiu, em 2013, suplantá-la. Já o Nordeste, teve um ligeiro aumento; no entanto, permanece aquém dessa meta. Com isso, conclui-se que o Brasil, de uma maneira geral, tem aumentado a cobertura do rastreamento, ultrapassando, em 2013, a meta dessa Organização.

Descritores: Neoplasias do colo uterino; Doenças do colo do útero; Colo do útero; Prevalência; Brasil/epidemiologia.

Apresentado no BRAINCOMS Medical Congress 2015, UNIFESP, São Paulo, SP.

1. Acadêmicos do Curso de Medicina da Universidade Federal de Pelotas. Emails: william.zibetti@yahoo.com.br; thaisvicentinexavier@ hotmail.com.

1. Professor Doutor da Faculdade de Medicina da Universidade Federal de Pelotas. Email: mcapilheira@hotmail.com.

Endereço para correspondência: Avenida Presidente Juscelino Kubitschek de Oliveira, 3686. Pelotas, RS, Brasil. CEP:96080-116. 
ABSTRACT: Background: Cervix cancer is caused by the persistent infection by some oncogenic strains of the Human Papiloma Virus. It happens due to the abnormal growth of cells that have the capacity of locally invade and metastatize to distance. Cervix cancer is the third more frequent tumor among women and the fourth greater cause of death due to cancer in this population. For this reason, the cervix cytological examination becomes fundamental to track and diagnose this pathology, avoiding a metastatic role of it. Objectives: To determine the prevalence of the cervix cytological examination in the years 2007 and 2013, in all regions of Brazil, and compares them. Methods: Descriptive cross-sectional study, based on a secondary data of Chronic Diseases Risk and Protection Factors Vigilance by Telephone Inquiry (VIGITEL) of years 2007 and 2013. VIGITEL's objective is to monitor the frequency and distribution of noncommunicabel chronic diseases main determiners by phone inquiry. This questionnaire is anually performed since 2006 and, from 2007 on, questions about cancer prevention were included, being 2013 data the latest available up to the moment. The present research is performed with adults over 18 years old, residentes in the 26 capital cities of Brazil and Federal District. The outcome approached the performance or not of preventive cervix cancer examination at some point and in the last 3 years, being included women between 25 and 64 years old. In 2007, 32704 women were interviewed and in 2013, 32653. This data was organized according to year and region for further analysis.

\section{INTRODUÇÃO}

A neoplasias representaram, no início do século XXI, um problema de saúde pública em todo o mundo. Segundo a Organização Mundial da Saúde (OMS) em 2012, houve 8,2 milhões de mortes por câncer no mundo e $30 \%$ desses casos poderiam ter sido evitados se determinadas medidas de prevenção tivessem sido tomadas ${ }^{1}$. Entre os variados tipos de cânceres já relatados, o câncer de colo uterino é responsável por cerca de 530 mil novos casos e 266 mil mortes por ano, no mundo ${ }^{2}$. No Brasil, é, respectivamente, o terceiro mais incidente e o quarto com maior mortalidade entre as mulheres ${ }^{3}$.

O câncer de colo uterino é causado pela infecção persistente por algumas cepas oncogênicas do Papiloma Vírus Humano. Ele acontece devido ao crescimento anormal de células que possuem a capacidade de invadir localmente e metastatizar à distância. Devido à sua alta incidência e elevado índice de mortalidade, o exame citopatológico de colo de útero mostra-se fundamental no rastreamento e diagnóstico precoce desta patologia, evitando, assim, que essa assuma um papel metastático ${ }^{3}$.

A prevenção primária do câncer do colo do útero (ou câncer cervical) está relacionada à diminuição do risco de contágio pelo papilomavírus humano (HPV). A transmissão da infecção pelo HPV ocorre por via sexual. Consequentemente, o uso de preservativos (camisinha) durante a relação sexual com penetração protege parcialmente do contágio pelo HPV, que também pode ocorrer através do contato com a pele 4 . Salienta-se, porém, que as cepas causadoras de lesões de pele não são
Results: In 2007, from all Brazilian women interviewed, $84.67 \%$ said they have already done the cervix cancer tracking examination, while $79.81 \%$ claimed to have it done in the last 3 years. By regions, South region was highlighted with $92.85 \%$ and $88.21 \%$, for the same variables. Northeast region had the lowest rates in the country, $80.12 \%$ and $75 \%$, respectively. Southeast region showed high rates, near South. Midwest was in third place, getting over North region. In 2013, 85.61\% of women said they have already done the examination at some point in life, and $80.68 \%$ were updated with it. By regions, South regions was again highlighted, with $92.75 \%$ of women having done the examination at some moment and $87.81 \%$ being updated with it. Northeast region had the worst performance, with $80.8 \%$ and $75.59 \%$, respectively. Still, the Midwest was supplanted by the North, after slight improvement of the later in relation to 2007. Discussion/Conclusion: South, Southeast and Midwest regions kept with high rates of the examination, similar to developed countries. In 2007, North region, which was under the coverage of $80 \%$ demanded by WHO, managed, in 2013, to supplant it. Northeast had a quick increase; however, it remains short of this goal. With this, it was concluded that in Brazil, in general, the tracking coverage has increased, overtaking, in 2013 , the goal of this Organization.

Keywords: Uterine cervical neoplasms; Uterine cervical diseases; Cervix uteri; Prevalence; Brazil/epidemiology.

aquelas mais oncogênicas.

Tanto a incidência como a mortalidade por câncer do colo do útero podem ser reduzidas com programas organizados de rastreamento. Este se baseia na história natural da doença e no reconhecimento de que o câncer invasivo evolui a partir de lesões precursoras (lesões intraepiteliais escamosas de alto grau e adenocarcinoma in situ), que podem ser detectadas e tratadas adequadamente, impedindo a progressão para o câncer. $\mathrm{O}$ método principal e mais amplamente utilizado para rastreamento do câncer do colo do útero é o teste de Papanicolaou (exame citopatológico do colo do útero $)^{5}$.

No Brasil, o Ministério da Saúde (MS), desde 1988, segue as recomendações da OMS, a qual preconiza, para a detecção precoce dessa neoplasia o exame de Papanicolaou, que deve ser oferecido às mulheres na faixa etária de 25 a 64 anos e que já tiveram atividade sexual. A rotina recomendada para o rastreamento no Brasil é a repetição desse exame a cada três anos, após dois exames normais consecutivos realizados com um intervalo de um ano $^{6}$.

\section{OBJETIVO}

Determinar as prevalências da realização do exame citopatológico do colo uterino nos anos de 2007 e 2013, em todas as regiões do Brasil, e compará-las.

\section{MÉTODOS}

O delineamento do estudo é do tipo transversal 
descritivo, com base em dados secundários da Vigilância de fatores de risco e proteção para doenças crônicas por Inquérito Telefônico (VIGITEL) dos anos de 2007 e 2013. O objetivo do VIGITEL é monitorar a frequência e distribuição dos principais determinantes das doenças crônicas não-transmissíveis por inquérito telefônico. Esse questionário é realizado anualmente desde o ano de 2006 e, a partir de 2007, foram incluídas perguntas sobre prevenção de câncer, sendo os dados 2013 os últimos disponíveis até o momento. Essa pesquisa é realizada com maiores de 18 anos residentes das 26 capitais brasileiras e no Distrito Federal. O desfecho do presente estudo compreendeu a realização ou não do exame preventivo do câncer de colo uterino em algum momento da vida e nos últimos 3 anos, sendo incluídas as mulheres entre 25 e 64 anos. No ano de 2007 foram entrevistas 32704 mulheres e em 2013, 32653. Esses dados foram agrupados segundo ano e região para posterior análise.

\section{RESULTADOS}

Em 2007 (Tabela 1), do total de brasileiras entrevistadas, 84,67\% responderam já ter realizado o exame de rastreio para câncer de colo uterino, enquanto $79,81 \%$ afirmaram tê-lo realizado nos últimos três anos. Por regiões, a Região Sul se destacou com percentuais de $92,85 \%$ e $88,21 \%$, para as mesmas variáveis. A Região Nordeste teve as piores taxas do país, com 80,12\% e $75 \%$, respectivamente. A Região Sudeste apresentou altos índices, próximos ao Sul. O Centro-Oeste ficou em terceiro, superando Região Norte.

Em 2013 (Tabela 2), 85,61\% das mulheres afirmaram já ter realizado o exame de rastreamento em algum momento da vida, e $80,68 \%$ responderam estar em dia com o exame. Por regiões, a Região Sul foi quem se destacou, com $92,75 \%$ das mulheres já tendo realizado o exame em algum momento e $87,81 \%$ estando em dia com o Papanicolau. A Região Nordeste teve o pior desempenho, com $80,8 \%$ e $75,59 \%$, respectivamente. Ainda, o CentroOeste foi suplantado pelo Norte, após melhora discreta deste último em relação à 2007. Após análise ajustada das variáveis foi encontrada significância estatística $(p<0,05)$.

Tabela 1. Distribuição por região do Brasil das mulheres que realizaram o exame de Papanicolaou, VIGITEL 2007

\begin{tabular}{|c|c|c|c|c|c|}
\hline \multirow{2}{*}{ Região } & \multicolumn{2}{|c|}{ Em algum momento } & \multicolumn{2}{|c|}{ Nos últimos 3 anos } & \multirow{2}{*}{$\begin{array}{c}\text { Valor } \mathbf{p} \\
<0,05\end{array}$} \\
\hline & $\mathbf{n}$ & $\%$ & $\mathbf{n}$ & $\%$ & \\
\hline Sul & 3.381 & $92,85 \%$ & 3.212 & $88,21 \%$ & \\
\hline Sudeste & 4.270 & $88,1 \%$ & 4.061 & $83,78 \%$ & \\
\hline Centro-Oeste & 4.100 & $86,18 \%$ & 3.870 & $81,35 \%$ & \\
\hline Nordeste & 8.935 & $80,12 \%$ & 8.363 & $75 \%$ & \\
\hline Norte & 7.005 & $84,31 \%$ & 6.594 & $79,36 \%$ & \\
\hline Brasil & 27.691 & $84,67 \%$ & 26.100 & $79,81 \%$ & \\
\hline
\end{tabular}

Tabela 2. Distribuição por região do Brasil das mulheres que realizaram o exame de Papanicolaou, VIGITEL 2013

\begin{tabular}{|c|c|c|c|c|c|}
\hline \multirow{2}{*}{ Região } & \multicolumn{2}{|c|}{ Em algum momento } & \multicolumn{2}{|c|}{ Nos últimos 3 anos } & \multirow{2}{*}{$\begin{array}{c}\text { Valor } \mathbf{p} \\
<0,05\end{array}$} \\
\hline & $\mathbf{n}$ & $\%$ & $\mathbf{n}$ & $\%$ & \\
\hline Sul & 3.417 & $92,75 \%$ & 3.235 & $87,81 \%$ & \\
\hline Sudeste & 4.455 & $90,31 \%$ & 4.206 & $85,26 \%$ & \\
\hline Centro-Oeste & 4.195 & $85,87 \%$ & 3.961 & $81,08 \%$ & \\
\hline Nordeste & 8.919 & $80,8 \%$ & 8.344 & $75,59 \%$ & \\
\hline Norte & 6.970 & $85,92 \%$ & 6.600 & $81,36 \%$ & \\
\hline Brasil & 27.956 & $85,61 \%$ & 26.346 & $80,68 \%$ & \\
\hline
\end{tabular}

\section{DISCUSSÃO/CONCLUSÃO}

O câncer de colo uterino acontece devido ao crescimento anormal de células que possuem a capacidade de invadir e espalhar-se para outras partes do corpo ${ }^{7}$. Tipicamente, em seus estágios iniciais, não há sintomas. Sintomas tardios podem incluir sangramento vaginal anormal, dores pélvicas ou dores durante relações sexuais. ${ }^{8}$

Existem vários meios de se tentar combater o câncer de colo uterino, tanto depois do diagnóstico como também de uma maneira preventiva. Uma das principais formas é o exame preventivo (Papanicolaou), o qual é muito importante, pois esta doença se desenvolve 
gradativamente - por isso a necessidade do exame ${ }^{9}$. Outra forma de prevenção do câncer cervical é o uso da vacina. Existem duas vacinas contra o HPV (Gardasil e Cervarix) que reduzem o risco de mudanças cancerígenas no cérvice e períneo em cerca de $93 \%$ e $62 \%$, respectivamente ${ }^{10}$. Vacinas contra HPV são tipicamente aplicadas em mulheres entre 9 e 26 anos de idade, uma vez que a vacina só é efetiva antes da ocorrência da infecção ${ }^{11}$. Estudos mostram que, mesmo dentre profissionais da saúde, não é de conhecimento comum a existência da vacina, segura e efetiva. Embora essa vacina exista, ela ainda não é de fácil acesso à população em geral ${ }^{12}$. O Ministério da Saúde implementou no calendário vacinal, em 2014, a vacina tetravalente contra o HPV para meninas de 9 a 13 anos de idade. Esta vacina protege contra os subtipos 6, 11, 16 e 18 do $\mathrm{HPV}^{13}$.

As regiões Sul, Sudeste e Centro-Oeste mantiveram-se com altas taxas de realização do exame, semelhante a de países desenvolvidos ${ }^{1,7}$. Essas altas prevalências de realização do exame são corroboradas pelos resultados obtidos nos estudos de GASPERIN ${ }^{14}$ e Hackenhaar ${ }^{15}$. Em 2007, a região Norte que estava abaixo da cobertura de $80 \%$ estipulada pela OMS conseguiu, em 2013, suplantá-la. Já o Nordeste, teve um ligeiro aumento; no entanto, permanece aquém dessa meta (Figura 1). Com isso, conclui-se que o Brasil, de uma maneira geral, tem aumentado a cobertura do rastreamento, ultrapassando, em 2013, a meta dessa Organização.

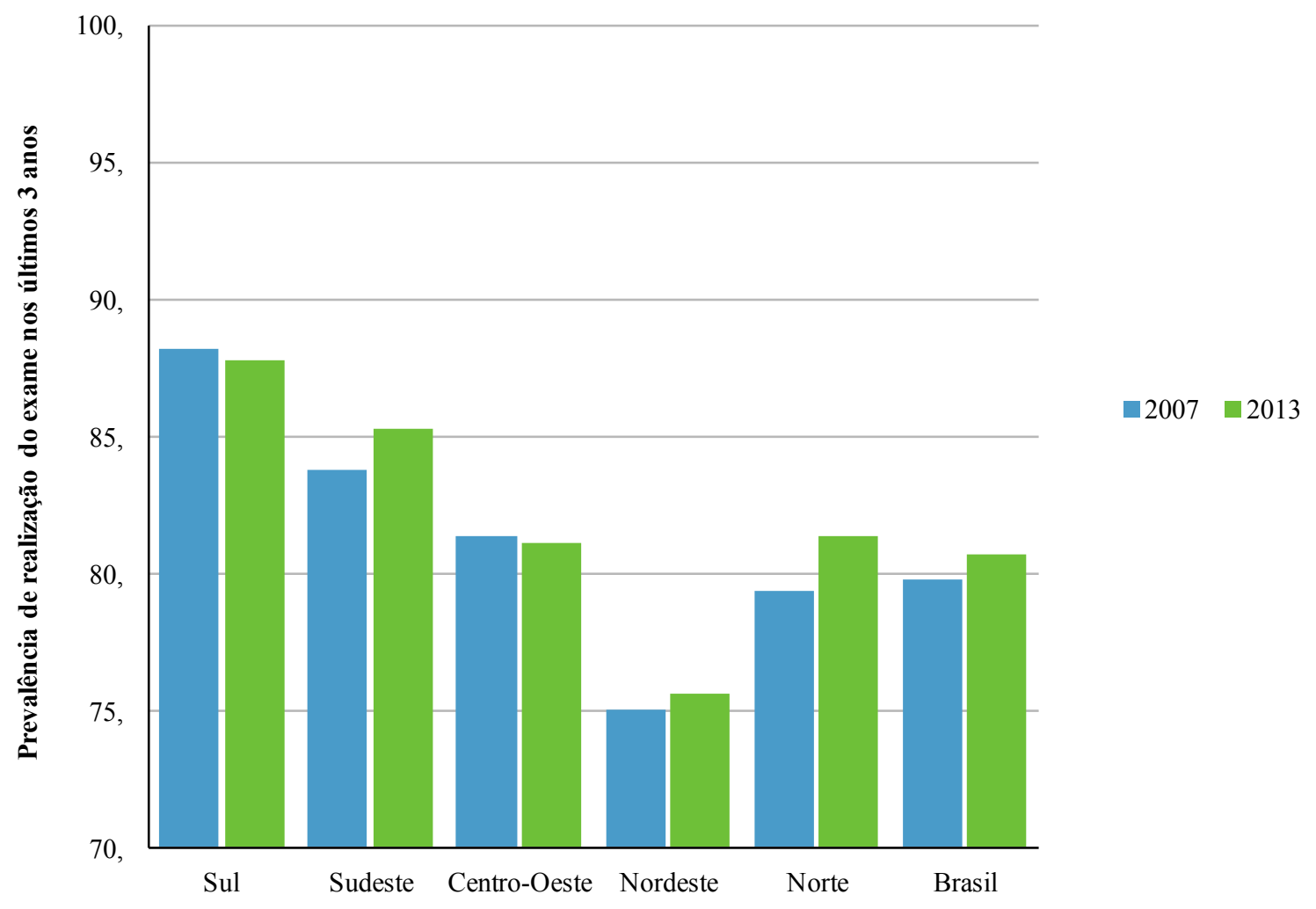

Figura 1. Prevalência de realização do exame de Papanicolaou nos últimos 3 anos, no Brasil, VIGITEL 2007/2013

\section{REFERÊNCIAS}

1. World Health Organization (WHO). Reproductive cancers; publications; cancers. Available from: http://www.who.int/ reproductivehealth/publications/cancers/en/.

2. World Health Organization. International Agency for Research on Cancer. Globocan 2012. Available from: http:// globocan.iarc.fr/.

3. Instituto Nacional de Câncer (INCA). Disponível em: http:// www2.inca.gov.br/wps/wcm/connect/tiposdecancer/site/ home/colo_utero/definicao.

4. World Health Organization. Cancer control. Knowledge into action. WHO guide for effective programmes. Geneve; 2007. Available from: www.who.int/cancer/modules/ Prevention\%20Module.pdf.

5. World Health Organization. International Agency for Research on Cancer. Globocan 2008. Lyon; 2008. Available from: http://globocan.iarc.fr/.

6. Brasil. Ministério da Saúde. Controle dos cânceres do colo útero e da mama. Brasília; 2006.

7. United States. National Cancer Institute. Defining cancer. Washington, DC: NCI, U.S. Government. 
8. United States. National Cancer Institute (US). Cervical cancer treatment $\left(\mathrm{PDQ}{ }^{\circledR}\right)$. Washington, DC: NCI, U.S. Government; 2014.

9. Lima CA, Palmeira JAV, Cipolotti R. Fatores associados ao câncer do colo uterino em Propriá, Sergipe, Brasil. Cad Saúde Pública. 2006;22(10):2151-6. http://dx.doi. org/10.1590/S0102-311X2006001000021

10. Medeiros LR, Rosa DD, da Rosa MI, Bozzetti MC, Zanini RR. Efficacy of human papillomavirus vaccines. Int J Gynecol Cancer. 2009;19(7):1166-76. doi: 10.1111/ IGC.0b013e3181a3d100.

11. United States. National Cancer Institute. Human Papillomavirus (HPV) vaccines: Q \& A. Fact sheets: risk factors and possible causes. Washington, DC: NCI; 2009.

12. Villar LM, Rabello AD, de Paula VS. Evaluating knowledge about human papillomavirus infection among
Brazilian health professionals. Asian Pac J Cancer Prev. 2011;12(12):3251-6. doi: 10.1111/IGC.0b013e3181a3d100

13. World Health Organization (WHO). Cancer control. Knowledge into action. WHO guide for effective programmes. Geneve; 2007. Available from: www.who.int/ cancer/modules/Prevention\%20Module.pdf.

14. Gasperin SI, Boing AF, Kupek E. Cobertura e fatores associados à realização do exame de detecção do câncer de colo de útero em área urbana no Sul do Brasil: estudo de base populacional. Cad Saúde Pública. 2011;7(27):1312-22. http://dx.doi.org/10.1590/S0102-311X2011000700007

15. Hackenhaar AA, Cesar JA, Domingues MR. Exame citopatológico de colouterino em mulheres comidade entre 20 e59 anosemPelotas, RS: prevalência, focoefatoresassociados à sua não realização. Rev Bras Epidemiol. 2006;1(9):10311. http://dx.doi.org/10.1590/S1415-790X2006000100013. 